American Journal of Qualitative Research

June 2019, Vol.3 No. 1, pp. 93-116

https://doi.org/10.29333/ajqr/5813

(C) 2019 AJQR. http://www.ajqr.org
AMERICAN

JOURMAL OF QUAUTATIVE

RESEARCH

ISSN: $2576-2141$

\title{
Imprint of Racism: White Adult Males' Transformational Experience from Racial Antipathy to Racial Reconciliation
}

\author{
Wynona Y. James ${ }^{1}$ \\ Nova Southeastern University
}

\begin{abstract}
Since the election of the first African American president in 2008, race relations have deteriorated in the United States. In May 2017, the emergence of the "alt-right" movement advocating for white nationalism caused further polarization between the races. This transcendental phenomenological research examined how white adult males' exposure to racist ideologies influenced their perceptions towards African Americans, and how they emancipated from environments that promoted racist tenets. The study was guided by three research questions: How have white males been impacted by their exposure to racial antipathy and discrimination? What events or circumstances have white males experienced that led them to denouncing negative racial stereotypes and/or participation with hate groups? And, what efforts have they made to reconcile with individuals or groups they have harmed in the past? The literature review revealed racial conflict is a social phenomenon evolving from historical narratives posited by fear, social class, and white superiority. By employing qualitative data analysis, interviewing eight participants, and applying the theoretical lenses of critical race theory, social Darwinism, hate theory, and regenerative justice, the primary essence of the phenomenon acknowledged individuals are mentally and emotionally affected by negative historical narratives about racism. Six major themes evolved: 1) Familial Influences, 2) Southern White Experience, 3) Education and Race Relations, 4) Spiritual Convictions, 5) Immersion into the African American Experience, and 6) Physical and Mental Emancipation. The findings in this study contribute to the field of conflict resolution by advocating for advanced exploration into socio-psychology, racial reconciliation, and restorative justice.
\end{abstract}

KEYWORDS: Racial Antipathy, White Males, Transformation, Qualitative Research, Transcendental Phenomenology, Racial Reconciliation

\section{Introduction}

Since 2008, the United States has experienced a substantial rise in racially motivated incidents related to outspoken commentaries on racial superiority and crimes perpetuated against African American citizens. During the summer of 2016, a number of major race related incidents

${ }^{1}$ Email: wj157@mynsu.nova.edu 
occurred between law enforcement and African American citizens resulting in more than 250 altercations - with many resulting in fatalities. Other incidents have resulted in African Americans being traumatized and killed by whites who aligned with ideologies and actions associated with white supremacy. In 2015, a young white man named Dylann Roof entered a historically African American church in Charleston, South Carolina while nine African American church member and a state representative were participating in their weekly Bible study and prayer meeting. Dylann Roof riddled them with bullets after he had sat and participated in the group's study and prayer time for more than an hour. Thereafter, he said, "he had to kill them because the African American race was taking over" (Ward, 2015), and he professed being an advocate of the U.S. Confederacy. The aftermath in all incidents continues to create major rifts and racial divides, particularly between some members of the African American and white races.

In 2014, a group was organized to advocate for civil rights and equality for African Americans and became known as the Black Lives Matter Movement. The group made major strides in addressing racial profiling, police brutalities, and social inequities towards blacks and other non-white citizens in the United States. Although the organizers have had successful outcomes in their efforts, they have also been met with major resistance from opposition groups such as the National Policy Institute (NPI), led by Chairman and white supremacist Richard Spencer. The NPI is located in Arlington, VA and advocates for the United States to be a pure race nation (Mascaro, 2016).

In 2017, hundreds of individuals associated with neo-Nazi groups, white nationalists and white supremacists convened at the University of Virginia, and marched through the streets of Charlottesville carrying fire torches and yelling, "Jews will not replace us" (Rosenberg, 2017). The incident resulted in a major confrontation with counter-protesters and a 20-year old motorist, James Fields driving his car into a crowd injuring approximately 19 individuals and killing a 32year old white peace marcher, Heather Heyer (McCausland et. el., 2017).

The results of this level of unconscious assumptions has contributed to how blacks are treated when it comes to law enforcement. Blacks are more likely to be arrested and incarcerated than whites. The Pew Research Center (2013) conducted a study in 2013 and concluded that black men are six times more likely to be incarcerated than white men. As recently as January 2018, a YouTube video featured U.S. Senator Cory Booker stating during a Senate hearing that "the Government Accounting Office (U.S. Government Accountability Office, 2017) published a report that cited out of 85 violent extremist incidences that resulted in deaths since September 2001, far right-wing violent extremists were responsible for $73 \%$ of crimes. Of the 85 violent extremist incidences, $73 \%$ were committed as bigotry and hate against minorities" (Conservative vs. Liberal Beliefs, 2018; U.S. Government Accountability Office, 2017).

\section{Literature Review}

The literature for the study identified that there has been a large number of research studies conducted on racial antipathy and the conflict between the Black and White races (Ahmed, 2016; Alexander, 2012; Branch, 1998; Bullard, 2000; Curtin, 1972; Degruy, 2005; DuBois, 1998 [1899]; Dyson, 2017; Fleury, 2015; Garrow, 2004; Jordan, 1996; Kariuki \&Mbugua, 2018; Omi \& Winant, 2015; Roberts, \& Klibanoff, 2006; Wallis, 2016; Washington, 2006; West, 2001; Williams \& Mohammed, 2013).

The literature review revealed that individuals have the potential to transform their lives from past participation with extremist hate groups and racist ideologies (Blazak, 2004; Collins, 
2012; King, (personal communication, February 23, 2015); Leyden \& Cook, 2008; Mauch \& Tarman, 2016; Meeink, 2009; Michaelis, 2012; Mohr, 2010; Picciolini, 2017; Potok, 2013a; Potok, 2013b; Simi, 2003 Tarman, 2017).

The exploration of the literature revealed there is a gap in the literature as it pertains to understanding the emotional impact on individuals lives when they have chosen to denounce involvement with racial antipathy and transform their lives to embrace racial diversity and equality. Blazak (2004) and Simi, (personal communication, July 1,2016) posit that there is only a modest group of studies have been completed from the approach of how individuals have transformed their lives from racial hate toward reconciliation. According to Angela King (personal communication, February 23, 2015), more and more individuals are departing from hate groups and remain underground for fear of retaliation, harassment, or harm from active group members. Therefore, it is difficult to gather the narratives of the lived experiences and stories of their departure and their recovery from the groups (Blazak, 2004; King, (personal communication, February 23, 2015); Simi (personal communication, July 1, 2016)). This proved true during the recruitment phase of the study when efforts to communicate with former extremists became futile. Although formers (as they are called after departing extremist groups) are interested in sharing their past experiences, there is also a level hesitancy to communicate with others for fear individuals who are still active with the hate groups will harm them or retaliate against them (King, personal communication, February 23, 2015).

\section{Method}

Qualitative research methods afford researchers the opportunity to explore the experiences and meaning of the participants' life stories and events, in order to gain a full understanding of their lives, and to make sense of the experiences that are shared with the principle investigator (Creswell \& Poth, 2018; Creswell, 2009; van Manen, 1990). Clark Moustakas (1994), a strong proponent of phenomenological research, posits that research focuses on the whole of the experience of individuals and the substance of the experiences. Moustakas posits "the basic purpose of phenomenology is to reduce individual experiences with a phenomenon to a description of the universal essence - a "grasp of the very nature of the thing" (van Manen, 1990, p. 177)".

The purpose of the phenomenological study was to explore the lived experiences of white adult males who were born and raised in the United States and were exposed to racial antipathy and negative racial stereotypes towards members of the African American race. The study focused on the origins of racial antipathy, how it impacted the participants' lives, and their ability to transition towards racial reconciliation. Further exploration delved into the participants' environment, social connections, beliefs, and their ability to mentally and physically emancipate from their past.

The phenomenological method employed aided in understanding the transformational process the participants experienced as they moved from racial hate to racial equality and for those who may have departed membership with hate groups. The method concentrated on the subjectivity and relativity of real-life situations in an effort to understand how humans view themselves and the world around them. As such, the phenomenological researcher will attempt to differentiate the "phenomena (the perception or appearances from the point of view of a human) from the noumena (what things really are)" (Willis, 2007, p. 53). 


\section{Transcendental Phenomenology}

The transcendental phenomenological design is based on principles identified by Husserl (1931) and translated into a qualitative method by Moustakas (1994), which holds the promise as a viable procedure for phenomenological research. The uniqueness of this design method is that it focuses on understanding the lived experiences of individuals. The transcendental phenomenological analysis method was used for the study to dissect and comprehend oral narratives of individual's life experiences to gain an in-depth understanding of what the experiences mean to individuals and why they hold them in such esteem (Creswell \& Poth, 2018). Transcendental phenomenology is valuable in the exploration of the participants' narratives and interpretation of the events because it honors the lived experiences of participants and seeks to determine the common themes.

This method also aided in gaining a meaningful understanding of the historical events the participants have experienced and what seems to be positive transformations from ideologies of hate to reconciliation (Creswell \& Poth, 2018; Patton, 2002). According to Michael Patton (2002), the inquiry of qualitative approach provides the investigator with tools and resources that aid in the exploration of various social and cultural events and experiences. Through the application of interviews, observations, and documentation of events and phenomenon, data will reveal conclusions that either validate or dismiss hypotheses and questions that were previously developed.

\section{Participants}

The development of a participant pool commenced in January 2015 after the Institutional Review Board (IRB) at Nova Southeastern University approved the investigator's initial research protocol to perform the study. During this period, the focus was primarily on individuals who had previous affiliations with extremist hate groups in the United States and, at some point in their life, elected to denounce their participation and became advocates for racial equality and racial reconciliation. The Southern Poverty Law Center (SPLC) in Montgomery, Alabama was instrumental in providing recommendations for recruiting participants for the study. The SPLC is a national organization that has been instrumental in monitoring the activity of extremist hate groups in the United States. Due the sensitive nature of the exploration on the topic of racial antipathy and hate groups.

Since most individuals who are associated with hate groups are done in secret, it was not possible to publicly advertise for volunteers. For the protection of the prospective participants and their personal security since departing the organizations, the process of snowball sampling was implemented. This included communicating through academic colleagues, other researchers, and participants who may have acquaintances who would have an interest in participating in the study.

During the initial recruitment of participants in 2015, the SPLC recommended five individuals between the age of 35 to 62 to consider contacting for the study and were former members of extremist hate groups. The individuals were contacted by phone and email to discuss the intent of the study. The prospective recruits resided from Miami, Florida, Blue Island, Illinois, Milwaukee, Wisconsin, Abilene, Texas, and South Philadelphia, Pennsylvania; and grew up in broken homes or without a father. Prior to departing the hate groups, they were affiliated with, 
they were active members and strong proponents with neo-Nazi skinhead movements, White Aryan Resistance (WAR), white supremacist skinhead gang, and a religious extremist group known as the Covenant, The Sword, and the Arm of the Lord.

Contact was made the recommended participants and preliminary arrangements were made to interview them. From this process, four individuals agreed to schedule interviews and one individual completed the interview session. The process to schedule and complete interviews with other prospects became arduous and unpredictable. Therefore, in 2016, an amendment was made to the IRB protocol to broaden the participation to the general population for recruits, and the focus of the study expanded to explore the lives of individuals who had been exposed to racial antipathy through family, friend circles, and/or other agencies (e.g. school, church, social organizations).

The effort to broaden the recruitment to the general population of white males in the study resulted in finalizing the participant pool to include eight white adult males between the ages of 29 and 72 and were born and raised in the United States. All participants had at least a high school education, with three out the eight participants attaining graduate level degrees. The participants were from various regions of the Pacific Northwest, Southwest, and the Southern United States. Individuals were recruited until the participant pool for the transcendental phenomenological model was met and participants had equitable experiences (Moustakas, 1994). Efforts were employed to ensure the utmost level of integrity and minimum risks to the participants were adhered to. To maintain the confidentiality and safety of each individual who participated in the study, each participant was assigned pseudonyms for the names of participants, and these were used during the oral interviews, written transcription of interviews, the research process, and publication of the study. The men who elected to participate signed the consent form and they returned them to me by email or in person. Thereafter, I scheduled the day and time for each interview session and provided each participant with a copy of their consent form with my signature, acknowledging receipt of their consent forms.

\section{Procedure}

The study applied the research method of transcendental phenomenological research for the purpose of gleaning a deeper understanding of the participants lived experiences and their transition from environments that embraced racism to racial reconciliation (Creswell, 2012). The effort to collect background information on the participants was facilitated by interviews conduct by telephone with each participant. Eight interviews were accomplished with each interview averaging 90 minutes.

During each interview session, participants shared their lived experiences as they related to them growing up in homes or other social settings that exposed them to racial antipathy, discrimination, and stereotyping African Americans. Most of the participants shared the period in their lives when they began to explore and understand ethnic and cultural differences which contributed to them denouncing the negative racist tapes and emancipation from groups that advocated for discrimination and segregation. The participants consented to having their interviews recorded and thereafter, the recordings were transcribed for the purpose of completing the coding and analysis.

The application of transcendental phenomenology became the impetus for exploring the lived experiences of individuals who were either exposed to, or participated in, racial antipathy and how the experiences ultimately led to their decision to denounce racist ideologies. The research design, sampling type and sample size, bracketing, interview process and questions to be used, 
research ethics, confidentiality, standards of conduct, and the process of data collection and analysis will also be discussed.

\section{Phenomenological Analysis and Step-by-Step Process}

After all the interviews were conducted with each participant and the transcriptions were accomplished, the investigator began to organize and analyze the material through the methods and procedures of phenomenological analysis as prescribed by Moustakas (1994) and the research group, Stevick, Colaizzi. and Keen as cited in Moustakas (1994). The completed transcriptions totaled close to 500 pages of documentation which were organized in a notebook with each participant having their transcripts assigned by tabs and pseudonyms were assigned. This structuring of material allowed for sub-tabs to be added during the progression of each step of the analysis and provided quick cross-referencing of material. Once this phase was completed for preparing the data, the application of each step of the analysis as prescribed by Moustakas was accomplished in the following stages:

Step 1 - Horizonalization: The process of horizontalization is to "list every expression relevant to the experience" (Moustakas, p. 120). During this process, the review feature in Microsoft Word captured comments in the righthand column of the transcript. In the comment blocks, words, phrases, and quotes that related to the comments the participant shared during the interview were inserted. In addition to the words, phrases, and quotes, notations that explained how the comment related to a theory were cited in the theoretical framework that was established. Each statement made in each participants' individual transcript was reviewed that related to the research topic and questions, and equal value was to the statements identified. For each statement that related to the research was initially highlighted and a note made a on the statement through the Microsoft Word feature for highlighting and creating comments. In addition to the standard coding citing by Moustakas (1994), theories were included that seemed to align with the coding (e.g. words, adjectives, sentences, and phrases). This streamlined the analysis portion as the statements related to potential theories. Although assignment of theories to the codes is not a step from Moustakas' phenomenological process, it was a stage of the interpretation of data that was adapted from Dr. Robyn Gabe (2016), who constructed the step, which streamlines the data analysis. The process provided efficiency of the data when it was time to discuss the findings and conclusion of the study.

Step 2-Reduction and Elimination: Reduction and elimination is used to "determine the Invariant Constituents: by testing each expression for two requirements: a) Does it contain a moment of the experience that is a necessary and sufficient constituent for understanding it? $b$ ) Is it possible to abstract and label it? If so, it is a horizon of the experience. Expressions not meeting the aforementioned requirements are eliminated. Overlapping, repetitive, and vague expressions are also eliminated or presented in more exact descriptive terms. The horizons that remain are the invariant constituents of the experience" (Moustakas, 1994, pp. 120-121).

During this process, each transcript was highlighted from the horizontalization stage and began a color code method that identified experiences that were sufficient and labeled the experiences. It was during this step in the color coding a word, adjective, title or simple sentence were assigned that defined the experiences. This process was accomplished on each transcript and resulted in over 1,000 notations.

Step 3 - Clustering and Thematizing the Invariant Constituents: According to Moustakas, the investigator will "cluster the invariant constituents of the experience that are 
related into a thematic label. The clustered and labeled constituents are the core themes of the experience" (p. 121). At this stage of the analysis, previous highlights and coding accomplished in Steps 1 and 2 were expanded on, and then the clustering of information was established. Through the use of the electronic files established on each participant, interview notes and highlights were reviewed and assigned to grouping during horizonalization which placed like codes and statements together. Once this was done for each participant's data, a combination of all the participants' information evolved into a new document that identified the core themes.

Step 4 - Final Identification of the Invariant Constituents and Themes by Application: Validation: In this step, the investigator is required to "check the invariant constituents and their accompanying theme against the complete record of the research participant. (1) Are they expressed explicitly in the complete transcription? (2) Are they compatible if not explicitly expressed? (3) If they are not explicit or compatible, they are not relevant to the co-researcher's experience and should be deleted" (Moustakas, 1994, p. 121).

At this stage of the analysis, it was determined that all participants' experiences were relevant to the research and mutually aligned with one another. However, there were themes that reflected all participants having some experience with, while others were not as relevant. For example, themes that were secondary to the core themes included: class structure, economic race, grandparents, Jim Crow, stereotypes, and segregation. Yet, other themes were distinct enough to become the primary themes for consideration in the final interpretation of the data. These themes will be discussed in detail in the findings section of Chapter 5.

Step 5-Evolution of the Textural Descriptions: Moustakas posits that "using the relevant, validated invariant constituents and themes, the investigator is required to construct for each coresearcher [participant] an individual textural description of the experiences that includes verbatim examples from the transcribed interview" (p. 121).

At this stage of the analysis and findings, 26 core categories identified. Through copious reading and contemplation on each transcript and clusters, six major themes began to evolve from the original 26 primary categories that were identified. Each theme evolved by reading all the participants' transcripts and extrapolated narratives that directly aligned with the theme.

Once the primary themes were identified and a determination of the relationship between the six was recognized, the evolution of a topic was crafted. With each of the six themes, an overview was presented - along with the interpretation of the theme and summary of each theme's relationship to the literature review, research questions, and theories applied to the study.

Step 6 - “Construct each Co-Researcher's [participant] Individual Textural Description of the Experience" (Moustakas, 1994, p. 121): Once the themes and selected narratives were identified from each participant's transcript, creation of the textural and structural description of the participants' experiences were accomplished (Creswell \& Poth, 2018). A written summary of each participant's experience as it relates to the data collected and the themes identified in this study was also completed. According to Moustakas (1994), the last stage of the data analysis was to develop a description of the meanings and essences of the experience as it represents the group.

\section{Results}

The study resulted in the identification of six themes that emerged and aligned with the essence of individuals recovering from past experiences that advocated for racist ideologies and discrimination. The six themes are: familial influences, the white experience, education and race relations, spiritual convictions, immersion into African American experience, and physical and 
mental emancipation. These themes also had sub-themes associated the experiences the participants described.

\section{Emergence of Themes}

Familial Influence. This theme aligns with the research question on how individuals have been impacted by their exposure to racial antipathy and discrimination. The men who participated in this study reflected on the relationships they had with their family members - particularly with their fathers, mothers, and grandparents. Many participants indicated their parents shared stories that had been passed down from generation-to-generation that portrayed members of the black race in a negative light. The participants recall their parents reinforcing the ideology that whites will always be superior to blacks. Other participants discussed the racial stereotypes and off-color descriptors their relatives used such as "N-word", "jungle bunnies", "drug pushers", "addicts" and "thuggish". Chuck stated: "My grandmother was more racist. I never heard my grandmother say the "N" word, but she would call them [black children] "Jungle Bunnies." I can remember my grandmother saying those kinds of names, not real often, but periodically." Ron stated: "When we moved to Missouri, our grandpa would call us on the phone from where he lives in West Virginia and would asked us (the first time I really noticed that something was a little bit weird was), if we had any colors at our school. And I didn't really get what he meant, just because that's an outdated term. When we first started going to the school, our grandpa called us on the phone. He lives in West Virginia, as well. I just remember being really confused. My mom and others thought it was a funny story because, you know, I have Asperger's, so I took it very seriously as a kid. I thought he meant, you know, they have different types of colors that you see, like, visually. And I didn't know he was referring to "colors" as people, specifically black people."

This theme correlates with the literature review that revealed past and present scholars, such as Charles Darwin (1958), Richard Herrnstein and Charles Murray (1994), and Margaret Sanger (as cited in Fleury, 2015), inferred that members of the black race are inferior to other races. These pundits allege members of the black race possess savage characteristics, and are susceptible, to a higher rate of crime (Darwin, 1981; Ham \& Ware, 2007; Mohr, 2010; Moore, 2007). Historical and present-day assertions made by some researchers and individuals associated with white supremacist groups have concluded that members of the black race are inferior to other races.

The findings and literature review aligned with the theoretical framework of critical race theory and social stratification that asserts that critical race theory validates how cultural and racial socialization have influenced the marginalization of African Americans in the United States. Critical race theory has been a catalyst for exploring issues related to a number of social disparities that preclude African Americans from competing equitably with whites when it comes to economics, legal reasoning, enlightenment rationalism, and neutral principles of constitutional law. (Delgado \& Stefancic, 2012; Kendi, 2016). Aguirre and Turner (2009) assert that social stratification places focus on how discrimination creates an overrepresentation of members in an ethnic subpopulation in various social classes, resulting in a mobilization of power in order for one group of individuals to feel superior to those identified as lower class.

The findings identified that fathers of the participants had a strong presence in their lives. The participants recalled the strong disdain and resentment their fathers had towards blacks, with one participant stating his father acknowledged to him that if murder was not illegal, then his father would kill blacks. Other participants recounted commentaries their fathers made about their 
resentment that they had to report to black managers on the job. Some participants witnessed behavior from their fathers that was similar to split personalities. They explained how their fathers would behave one way around blacks and another way when they were around their white friends and associates. The literature review revealed similar assertions about white males' beliefs on white superiority and entitlements. The Emancipation Proclamation Act of 1863, the Reconstruction Era, and civil rights laws were implemented to establish equal rights and privileges for blacks; however, white citizens who identified themselves as segregationist and resisters to equality were very vocal and demonstrative in expressing their views on integration. The hate and disdain from segregationists and anti-abolitionists were so vitriolic that they resorted to violent crimes and implemented lynch laws (Baptist, 2014; Harris, 1984; Kendi, 2016; McCullough, 2016; Zangrando, 1980;). The theory of hate and economic race theory align with these findings and literature review. The hate theory posits the evolution of hate is manifested when an individual or group perceives another group or individuals believe they will lose rights or privileges. Schaefer and Navarro (2003) posits there are seven successive stages of hate: "1) Grouping (haters love company), 2) Defining through identification of symbols (e.g. tattoos, flags, and emblems), 3) Disparaging - verbally debasing objects they hate, 4) Taunting - rhetoric and violence, 5) Attacking without weapons - vocally abusive to physical abuse, 6) Attacking with weapons, [and] 7) Destroying" (n.p.).

All participants acknowledged that they had positive relationships with their mothers, and the majority of them defined their mothers as peacemakers. There were some participants who believed their mothers' opinion of blacks were motivated by them being influenced by their fathers' opinions.

Other participants believed historical inferences about blacks that their mothers heard were from their parents who had an influence on how their mothers interacted with blacks. For example, one participant stated that his mother told him the water fountains were separate because the black from African Americans' skin would get into the water. The participant Blaine stated: "Just typical proximity to a black person had a bit of discomfort to it. That was instilled. And you know I'm ashamed to say this now, this is, in fact, true that back then the thought of drinking from the same water fountain, which was forbidden in those days, but the thought of drinking from the same water fountain as an African American would instill kind of a gut level sense of aversion. It was an "Oh, yuk" kind of a thing."

Another participant recalled his mother witnessing a black couple kissing in public and was disgusted with what she had observed. Similar instances were identified from the literature review and the discussion on implicit bias and institutional racism. Levinson (2007) and Dovidio, Gaertner, Kawakami, \& Hodson (2002) assert that actions of racial bias affect racial equality when individuals become selective in what individuals choose to remember or recall about blacks and Americans. These individuals also acknowledge that racism exemplified by some whites can be unconscious, subtle, and not intended; however, the long-term effect on race relations can be systematically damaging and has the ability to diminish effective communication and to foster distrust. The theories that align with the findings and literature review are the critical race theory and social stratification theory - both of which posit that cultural and racial socialization influence the marginalization of African Americans. As such, members of the black race are not afforded equitable rights and privileges as whites in America (Delgado \& Stefancic, 2012; Kendi, 2016).

The relationship some participants had with their grandparents was not as extensive as they had with their mothers and fathers; however, the participants recognized that their grandparents' narratives about blacks were similar but somewhat colorful when they described blacks. Some 
participants recalled their grandparents using terms like "jungle bunnies", "colors", and "niggers." Some participants reflected on their experiences living with their grandparents and how they had property that had housed blacks from one generation to another since the Reconstruction period. Although the participants offered housing to blacks, they maintained certain social protocols. The findings from the participants experience correlate with the literature review's revealing of historical events where racial oppression and polarization occurred from slavery to the present.

The literature review identified a historical chronology that has promoted racial superiority and the marginalization of blacks in the United States that dates back to origins of slavery. Although efforts occurred to equalize the races through the inception of the Emancipation Proclamation of Act of 1863, Reconstruction, and civil rights laws, the nation continues to struggle with equality and social justice (Alexander, 2012; Branch, 1988; Bullard, 2000; DuBois, 1998 [1899]; Dyson 2017; Garrow, 2004; Roberts \& Klibanoff, 2006; West, 2001; Williams \& Mohammed, 2013). One Aguirre and Turner (2009) posit that social stratification theory focuses on how discrimination creates an overrepresentation of members in an ethnic subpopulation in various social classes resulting in a mobilization of power in order for one group of individuals to feel superior to those identified as lower class. For example, from the perspective of some participants' grandparents, they offered housing arrangements for blacks on their property, yet they did not have much interaction with blacks unless it benefited their welfare.

The White Experience. Most of the participants discussed their experiences growing up in white communities and schools. Some of the participants recognized that they had been influenced by the historical narratives and commentaries about white culture and elitism. Many participants recalled experiences where their fathers indoctrinated them to believe they would always be better than blacks because they were white. Others discussed their experiences with Jim Crow laws and whites' resistance to complying with laws related to desegregation. The white segregationists acted on their resistance to the civil rights laws related to desegregation by building private schools for only white children to attend. Other participants discussed standards of how they were to communicate with blacks versus with their white peers.

The participant Henry recounted how his father felt that because of his race and status in his community, he was privileged and entitled. As such, Henry described how he believed his father would take advantage of African Americans in order to get what he wanted - even to the degree of taking from poor African Americans. Henry stated: "I have served Medicaid clients, did child protective services, and have worked in a community mental health clinic. I know when people are poor, they have limited resources and that going to the doctor is a privilege. So, as I look back on an event as an adult and I see that I went to a physician whose job was to serve the poor and I'm not poor, that that is striking to me. It says something about what a person values when they call up the community health department and said to a Medicaid physician, "You're going to serve my son today and give him a school physical because he forgot to get his physical". It was the public health department. So, it was racially diverse office."

Henry continued by emotionally sharing how he realized he could go anywhere to get his health needs met, but his father chose to abuse the services provided in the low income black community.

The literature review revealed that white segregationists' resistance spawned from the 1860s and the Emancipation Proclamation Act of 1863 being enacted to provide equal rights and privileges to black slaves (Ash, 2013; Baptist, 2014; Foner, 2005; Jordan, 1996; Kendi, 2016; Levine, 2005; Omi \& Winant, 2015). The same resistance occurred during the period of reconstruction when, as Edward Baptist (2014) asserts, "White resistance was brutal and widespread" (p. 408). The literature review and findings align with the critical race theory, and 
according to Delgado and Stefancic (2012), "there is the existence of a social system of whiteover-color ascendancy, which serves a critical purpose of manipulating the subservient group in psychic and material dominance" (p. 7).

The majority of participants in the study reflected on how they grew up in all-white communities in the south and how the leadership of the towns was resistant in complying with the 1954 U.S. Supreme Court decision Brown v. Board of Education that recognized segregated schools were unconstitutional and ordered the schools to be desegregated. Some participants recalled the emotional uproar of white residents and white segregationists' defiance in not integrating, but instead, building private schools for white children.

The literature review revealed that throughout American history, white segregationists have resisted equal rights for blacks. The literature identified recurring periods in American history where integration and equality were mandated by the federal government and whites resisted. The alternative to complying with integration laws was the establishment of racial eugenics, Jim Crow laws, and lynching laws. Institutional and structural racism are also seen in the findings where the participants discussed how it impacted them - particularly when it related to them attending private schools. The majority of the participants acknowledged they did not understand why the separation was needed. One participant stated that he wanted friends, and it did not matter what color they were.

Institutional racism is a form of discrimination that occurs when institutional procedures that have been established result in racial inequality based on opportunities that one group is afforded over another. According to Griffith et. al. (2007), institutional racism can be seen in a number of social establishments, such as employment and hiring practices, and the group or individuals with power preclude groups with less power from having the opportunity to advance equitably to their peers. Other areas affected can be housing, medical care, educational opportunities, and politics. As such, the findings show that the white segregationists' behavior correlates with the precepts of institutional racism. Two theories that align with the findings are the critical race theory and social stratification theory because the white communities who could afford to build private schools for their children were establishing boundaries between the haves and have-nots. These decisions posited by white segregationists also reinforced the notion that whites are entitled and superior.

White Privilege and Entitlements. The findings reflect the participants' experience with white privilege and entitlements. Some participants were transparent in acknowledging that their fathers instilled in them that they were better than blacks and would always be better. During the interviews, there were participants who expressed their disdain with their fathers' assertions of being racially superior. Some witnessed how their fathers treated blacks when they were one-onone and separate from a white group in public. One participant felt his father used blacks for his personal and professional gain, but privately, his father's comments exemplified hate and disgust with blacks. The participant Henry stated: "My Dad would interact with white people in a certain way, and he would then interact with black people in a different way. You know an example would be, so my Dad is a store owner and Barber. African Americans would come into his store and do business with my father and would buy items, but he didn't cut the hair of black people. In part because he wasn't trained to do that. It's an entirely different training, but...but in also in part because [pause] it was not [pause] socially not acceptable for that to happen, [pause] in that community. There were black barbers and there were white barbers. And, that is kind of how it was. I think my Dad had no interest in it and it was not socially acceptable. I remember [pause] African Americans in that community coming into the shop and wanting a haircut [pause] and my 
Dad sort of handling that by saying he had to go somewhere, he had to go to a meeting [pause] or do something not saying he would like to cut their hair [pause] but he couldn't because he was not trained to cut their hair."

The literature review revealed this form of racist intent has been part of the American racial climate. For example, Abraham Lincoln implemented the Emancipation Proclamation Act of 1863; however, according to Dilorenzo (2002), "Lincoln's main interest was not in opposing slavery but in advancing mercantilism, inflationism, and government spending: the 'American system' of Henry Clay" (p, 15). The reconciliation theory may align with the literature review and findings from the perspective that Lincoln attempted to reconcile the welfare of black slaves by ordering the Emancipation Proclamation; however, this may be questionable, because his decision of emancipation was implemented for political gain. According to Everett Worthington, Jr. (2001), the reconciliation theory addresses the concept of reconciliation and forgiveness and its relationship to biological, psychological, and social aspects of individuals' lives.

Education and Race Relations. This theme aligns with the research questions on how individuals have been impacted by their exposure to racial antipathy and discrimination toward African Americans, and what events or circumstances individuals experienced that led them to denouncing negative racial stereotypes and/or participation with hate groups. All participants shared unique experiences within the school systems they attended. The majority of the participants indicated they attended all-white schools; however, three participants attended integrated schools. The literature review referred to incidences of racial conflict where harm was imposed on blacks and those who were supporters of civil rights. The literature review did not identify specific conflict related to schools; however, the closest to school events would be the conflict that occurred when desegregation was ordered and President Dwight Eisenhower ordered the National Guard to escort black children to school in Little Rock, Arkansas.

Most participants acknowledged they attended all white schools that had been established to preclude compliance with desegregation. The participants were cognizant that they had no problems or racial issues because they interfaced with their own race. However, there were some participants who recognized later in life that they had missed the opportunities to meet people different than themselves. The literature review revealed that the same occurrences happened across the United States - particularly when the U.S. Supreme Court mandated desegregation in the 1950s. White citizens who resisted desegregation preferred the schools to remain segregated. The theories that aligned with the findings and literature review are the critical race theory, which has the unique ability to advance the cause of the white elites and working class while eliminating opportunities for African Americans (Delgado \& Stefancic, 2012, p. 8), and social Darwinism, which posits that there are intellectual differences between members of the black and white races. The theory of social Darwinism has played a significant role in impacting equality based on racial classification. Darwin was highly influential in increasing public opinion with some whites when Darwin inferred that the black race was biologically and intellectually associated closest with the species of apes (Darwin, 1958; Gould, 1977; Ham \& Ware, 2007).

While some participants attended segregated schools, other participants recalled their experiences attending integrated schools with blacks. The participants who attended predominantly black schools recalled that there were instances where racial conflict (e.g. fights, group disturbances) occurred; however, in both cases, they indicated that black students came to their aid, thus ensuring the participant was not harmed in the incidents. The literature review revealed that integrated schools originated from the U. S. Supreme Court's mandate to integrated schools in the Brown v. Board of Education case. The participants who attended integrated schools 
asserted that the schools were in the inner city or low-income communities, and they attended these schools because of the income level of their families. The findings and literature align with the social stratification theory, which distinguishes individuals or groups by class structure. Participants acknowledged that based on their income level, their families had no choice but to send their children to the black school systems.

The majority of participants recalled when they became inquisitive about the racist ideologies and perceptions they were taught from their parents, teachers, and the church. The experience involved them asking individuals such as their school teachers and Bible teachers about differences they recognized in the Bible and the daily pledge to the American flag. Some participants recognized that the pledge of allegiance declared "one nation under God" and "with liberty and justice for all." They pondered why they were not allowed to attend school with black students or do other social activities with them when the pledge specifically states there is only one nation and the close of the pledge refers to justice for all. The participants stated that when they asked their white instructors about the differences, the instructors shrugged off their questions and stated that those were questions and concerns that are not discussed. The same was true for participants who attended Sunday School and queried the teacher about Bible scripture stating that God recognizes everyone as equal. The participants recall the Bible teachers stating that those were things not discussed. Yet, the participants recognized there was a difference in what was being taught Biblically and academically than what the Bible states. It was moments like these in the participants' lives that motivated them to independently investigate what was right and wrong.

The literature review identified individuals who encountered experiences that motivated them to dispel racial stereotypes and negative perceptions. For example, Arno Michaelis (2012), in his book, Life after hate, recalled his encounter with a 90-year-old black woman during a visit he made to McDonald's restaurant. Michaelis is a former member of a hate group and detailed the experience and described how the woman who was in line with him asked Michaelis about the numerous tattoos. Michaelis described the moment the woman touched his arm and how the exchange with the woman impacted him. Michaelis indicated that the woman had no idea what the tattoos were about. The tattoos Michaelis donned on his arms were all symbols of white supremacy and hate.

The theoretical framework that interfaces with the findings and literature is the regenerative justice which "regenerative justice is the coupling of restorative justice with the notion of generative justice, which involves the explicit and intentional discovery and building of life meanings, as well as the consideration of the relationships that those meanings have with wrongdoing and "making things right" (Hansen \& Umbreit, 2018, p. 1).

Spiritual Convictions. This theme aligns with the research question regarding what events or circumstances the individuals experienced that led them to denouncing negative racial antipathy, stereotypes, and/or participation with hate groups and what efforts they have made to reconcile with individuals or groups if there was some sense of harm committed in the past. All the participants who were part of this study acknowledged they had either grown up in families that Christianity was central to or that they had previous exposure to religious activity. As the participants came to the age of reasoning, they began to ask questions about what they had been taught versus what they were reading in scripture or viewing from other sources (e.g. media, church, or social groups). Chuck recounted the time he was in Sunday school and how he became conflicted with the Sunday school making a distinction between blacks and whites. He stated: "I can remember in Sunday school, for example, when there was one time when the Sunday school teacher said that we believe in the Bible and the Bible answers everything in life and all that kind 
of stuff. I saw stuff on the news and so I asked my Sunday school teacher, "Well, what the Bible says about races?" Well, you know, you didn't talk about that kind of stuff in church in those days. So, I was cut off immediately by the teacher and she said, "Well, we don't talk about that kind of stuff."

The discussion in the literature review regarding the civil rights movement was pertinent to this theme. The civil rights movement led by Dr. Martin Luther King, Jr. aligned itself with nonviolence and Biblical principles related to peacemaking. Some participants acknowledged that the information they had grown up with, combined with the scriptural perspective Dr. King provided in his speeches, caused some participants to explore what was truth. The reconciliation theory and regenerative just aligned with the literature review and findings, and, as Hansen and Umbreit (2018) asserts, individuals recognized their exposure to racist ideologies caused harm to others. Once individuals recognized that they had been misinformed by racist stereotypes and ideologies, they began their personal quest to research the truth. The aforementioned commentary also supports the sub-themes related to the Biblical teachings in the participants' home versus what is accurately cited in Biblical scriptures and the participant's ability to become independent thinkers.

Immersion into the African American Experience. This theme and narratives the participants shared supported the research question about what efforts have the participants made to reconcile with individuals or groups. The majority of participants indicated that once they recognized the facts about the black experience were different from what they were taught as children, they were motivated to broaden their exposure to learn more about the black culture.

One participant [Blaine] cited that he really wanted to learn how to swim, and the only option available to learn from was his African American high school history teacher, who was also the swim coach for the school. The coach offered to teach Blaine how to swim. In order to have the lessons, Blaine had to swim in the pool for blacks. Blaine recounted how he not only learned to swim, but also recognized that the black community was lively, engaging and spirited - all of which was attractive to him. It also dispelled all previous stereotypes he had been informed of that related to black culture.

Henry spoke of his encounter with African American students while attending a state student enrichment program. Henry explained how the experience affected him and particularly when the African Americans teens encouraged him when he lost a competition. He stated: "When I was a senior in high school, I went to Boys State, which is, a national program and it's where students from all over the state go and they learn about the public process, about the political process. So, I went and there were students from all over the state from public and private schools and .... I did very well there. I was a candidate for Governor. I was one of the top two for Governor. I spoke in front of the entire Boys State. I won an award while I was there. After I lost the Governor's race, I was in my room with the door closed and the lights off just really depressed. And so, a group of about five or six black students (who I didn't know that well came to my room), came in and turned the lights on and started cheering me up. And it was one of the first times that I experienced the power of humor in the Black community and how they use that. There was an energy to it. I remember feeling the energy. I wasn't aware of it at that time, but they came in. They were teasing me in a very, sort of, light-hearted and friendly way, cheering me up, talking about their experiences, particularly with women, teasing me about my experiences with women, and the room just, I remember the energy in the room just transformed." From this experience, Henry began to question the stereotypes he had been introduced from his family and church experiences. 
The literature review revealed that past researchers, such as Charles Darwin (1958), Richard Hernstein and Charles Murray (1994), and Margaret Sanger (as cited in Fleury, 2015), concluded that members of the black race are inferior to other races. They alleged that members of the black race possess savage characteristics and are susceptible to a higher rate of crime (Darwin, 1981; Ham \& Ware, 2007; Mohr, 2010; Moore, 2007). However, from Blaine's and other participants' experiences, this was dispelled when they began to interact with blacks. The social Darwinism theory correlates to the findings and literature review by attempting to assert that there are racial differences between blacks and whites. Darwin (1958) posited blacks to be biologically and intellectually associated closest with the species of apes (Gould, 1977; Ham \& Ware, 2007). This misinformed assertion has been chronicled for centuries regarding the association between blacks and apes. Yet, the participants' personal initiative and engagement with the black community has eradicated these negative stereotypes. This commentary also addresses the subthemes related to the participants' ability to look beyond stereotypes.

The participants' exposure to blacks varied in their experiences with blacks. Some participants recalled experiences where they were befriended by a black instructor in high school or college. Others first experience with blacks occurred when they joined the military. The initial encounters were perhaps out of purpose but informative and cordial. Once the initial encounters were complete, the participants were motivated to explore more about the black peer's background, which resulted into a gradual development into a friendship.

All the participants acknowledged that they began to cultivate friendships when they were invited to participate in social activities or when they were integrated into the military culture. Some participants conceded that their first exposure to blacks was when they joined the military and experienced integration for the first time. The participants recognized that for the most part, the interracial relationships were accepted once blacks and whites got to know one another. The regenerative justice theory aligns best with this finding and the literature review. Hansen and Umbreit (2018) posit, "Regenerative justice is the coupling of restorative justice with the notion of generative justice, which involves the explicit and intentional discovery and building of life meanings, as well as the consideration of the relationships that those meanings have with wrongdoing and 'making things right"' (p. 1).

Physical and Mental Emancipation. This theme aligns with the research questions that explore how individuals have been impacted by their exposure to racial antipathy, discrimination, and stereotyping toward African Americans. The most profound transition for the participants was when they recognized that they want to exit from the racist environment they have been exposed to - for some participants, this can be years of exposure. The participants asserted they have had to liberate themselves from the racist environments (e.g. home, organizations, and communities) and mentally rehabilitate themselves to erase the negative mental racist tapes they were indoctrinated with during childhood. This theme aligns with the research questions that explored how individuals have been impacted by their exposure to racial antipathy, discrimination, and stereotyping toward African Americans. Most participants mentioned that once they left home and immersed themselves into African American communities and cultures, they realized that they had to work towards erasing the racist tapes were part of their memory.

The majority of participants said they decided to leave home in order to remove themselves from the racist environment. Most of the men were single when they departed and later married. Once the participants married and had families of their own, they made the painful decision to not return to the community and homes they grew up in because they did not want their children to be exposed to the environments that they were exposed to. 
The literature review identified individuals such as Frank Meeink (2009), Christian Picciolini (2017), and Arno Michaelis (2012) who desisted from racist environments such as the home or hate groups, which was similar to the participants' experiences.

The reconciliation theory and regenerative theory align with the literature and findings on individuals departing from racist environments and the participants' efforts to rehabilitate their lives from hate to reconciliation. Hansen and Umbreit (2018) posit that "regenerative justice is the coupling of restorative justice with the notion of generative justice, which involves the explicit and intentional discovery and building of life meanings, as well as the consideration of the relationships that those meanings have with wrongdoing and 'making things right" (p. 1).

Many of the participants were transparent in sharing how growing up in racist environments influenced their thoughts about blacks. Some of the participants acknowledged that it was important to remove themselves from the hate-based environment; however, some participants acknowledged that although they could physically remove themselves from the racist environments, they experience mental battles on a regular basis to dispel the negative ideologies and perceptions about blacks. One participant likened his experience to that of a recovering alcoholic who has to work on a daily basis to not allow the racist memories influence his current encounters and relationships with blacks. Joe stated: "In my mind, I knew I had racist and stereotypical thoughts placed in my head. You know those tapes you just don't erase even well into adulthood. You know when you got somebody in your family making inappropriate comments, those comments remain and you just have to determine where you going to file those thoughts. And, in sixth grade they were still near the front of my file cabinet in my mind. So, the turning point for me was realizing that I'm friends with these kids and I don't have issues on the surface with them. I also appreciated that they weren't going to physically assault me. That was a turning point because it never dawned on me that I swayed one way or the other with regards to race. I just try to assimilate and get through school. I think all children do, but on that day, I really had to think about race."

The literature review revealed the participants' assertions about the mental and emotional impact racism has on individuals' lives. Degruy's (2005) work with post traumatic slave syndrome identified that individuals can experience post traumatic slave syndrome as a result of the historical events related to racial conflict in America. The trauma not only impacts blacks, but also whites who witnessed and participated in events that harmed blacks. The reconciliation theory coincides with the literature review and findings on the mental impact that historical memories have on individuals' lives. Worthington (2001) focuses on the stress-and-coping theory of unforgiveness and forgiveness and how the concepts he proposes also align with reconciliation. Worthington's (2001) theory of reconciliation and forgiveness aligns with a portion of the research that explored the participants' stories and the conversion from hatred to self-reflection, from hate to compassion for others.

\section{Discussion}

The main focus in accomplishing this study was to bring attention to the fields of conflict analysis and resolution and social science on the topic of racial antipathy as it relates to historical stereotypes that have marginalized black Americans in the United States. Even though there have been countless written commentaries published over the years on racial disparities and racial antipathy, little was found on the exploration of how to reconcile the historical harms that have perpetuated generations of racial inequities and classified black Americans as inferior to the white 
race (Darwin, 1958; Fitzhugh, 1988; Hernstein \& Murray, 1994; Hitler, 1941; Sanger [as cited in Fleury, 2015]).

The literature review revealed only a small cadre of research has been published in the last 10 years on individuals' exposure to racial antipathy and cultural stereotypes that have misrepresented members of the Black race. The literature has been limited in exploring how individuals transformed their lives from the negative inferences and activities to appreciating the Black experience and cultivating rich interracial relationships with blacks. In order to grasp an understanding of the topic, a large amount of literature on a number of topics that relate to race antipathy and the racial conflict blacks and whites.

Some of the topics included: racial antipathy, historical stereotypes about race, white privilege and superiority, scientific assumptions and racial classification based on intellectual and physical factors, origins of slavery and racism, the Reconstruction Era in the United States, Jim Crow laws, the civil rights movement, institutional and structural racism, and economic disparities (Alexander, 2012; Branch, 1998; Bullard, 2000; Corona et al., 2017; Curtin, 1972; Degruy, 2005; DuBois, 1998 [1899]; Dyson, 2017; Fleury, 2015; Garrow, 2004; Jordan, 1996; Omi \& Winant, 2015; Onyolla, 2018; Roberts \& Klibanoff, 2006; Wallis, 2016; Washington, 2006; West, 2001; Williams \& Mohammed, 2013). The literature review identified individuals have the potential to transform their lives from past participation with extremist hate groups and racist ideologies (Blazak, 2004; Collins, 2012; King, personal communication, 2015; Leyden \& Cook, 2008; Meeink, 2009; Michaelis, 2012; Mohr, 2010; Picciolini, 2017; Potok, 2013a; Roy, 2009; Simi, 2003).

A select set of theories were explored to determine a relationship with the topic of racial discourse and their relationship with the research questions that best support the issues related to racial antipathy. The theory of social Darwinism became the central compass for the research and data analysis and how it has impacted the influence of racial classification and marginalization of Black Americans. Theories on the origination of hate and evil and critical race theory were also explored as they pertain to cultural and racial socialization and classification of racial groups and its influence on racial equality. The theory of social stratification was considered, as it relates to racial discrimination and the creation of overrepresentation of members in ethnic subpopulations in various social classes. This resulted in power and order of people based on perceived superiority. The theories of economic race and split labor market, based on social structure and political power instead of individual-level prejudices, were also examined. The theories are interconnected with one another and identified a pattern of racial stereotyping passed down from generation to generation with familial storytelling that showcased members of the Black race in a negative light. The theories support the notion of territorial ownership of resources and what occurs with individuals and groups when they believe their assets are threatened (e.g. changes in their community, employment privileges, social circles, mixed-races, economics, and politics).

The primary essence of the phenomenon is that racism has had a mental impact on the lives of white males and their ability to devoid themselves of the negative historical stereotypes about race. This essence epitomizes most participants, who defined themselves as being similar to recovering alcoholics. As such, some harbor resentment that their fathers exposed them to false inferences, racial hatred, superiority, and stereotypes towards members of the black race. The participants were very transparent in expressing how the mental guilt about their identity as a white male and member of the white race came with social and economic entitlements. Many stated that they fear that their past exposure to racist ideologies may inhibit their own thoughts and 
relationships toward blacks. Also, when leveled, social classification based on economic status seems to minimize racial conflict.

\section{Limitations}

The study was met with limitations that ultimately became a challenge for me. First, the solicitation of individuals to participate in a study became an arduous task in itself, and the study protocol was eventually amended to include the general population of the United States. Second, the lack of research accomplished on this specific topic and reconciliation was also a limitation. Blazak (2004), Mohr (2010), and Simi (2003) have conducted extensive research on racial antipathy and an individual's ability to desist participation with the group and have reported that limited research has been published on exploring individual's lives once they have removed themselves from the environments that advocated racist ideologies and how they emancipated from the homes and groups.

Blazak, Mohr, and Simi's studies focused on exploring members of extremist hate groups and white supremacy movements. However, the results of this study suggests that individuals do not have to be part of formal extremist groups to possess racist ideologies, and this study shows that individuals from the general population hold similar hatred and racist disdain for one another. Therefore, the research Blazak and Mohr accomplished correlate with the findings in this study. The literature review revealed that limited research has been accomplished on the topic of individuals' exposure to racial antipathy and cultural stereotypes that misrepresented members of the black race, and how the individuals transformed their lives.

\section{Contributions to the Discipline of Conflict Resolution and Social Science}

The study distinguishes itself by contributing to the disciplines of conflict resolution, social science, and psychology and provides insights into the lived experiences of white adult males born and raised in the United States and were exposed in their homes, communities, and social groups to segregation, racial antipathy, and racial discrimination and in their adult life emancipated from the racist environments. The study provides an opportunity for other studies to expand on the topic of individuals transitioning from racist environments and rehabilitating their perception towards blacks. One aspect of the study also revealed that individuals who depart racist environments continue to struggle with the past historical racist tapes. This is particularly true when individuals were exposed to the ideologies as children.

Another area of consideration is to focus future studies on the emotional impact individuals experience when they transition from the racist ideologies and emancipate from the negative environments. Two participants indicated that they routinely deal with emotional trauma from the experiences they were exposed as children until they left home. Part of my research identified that post-traumatic stress is not unusual. Degruy (2005) has written on the subject of post-traumatic slave syndrome (PTSS) and asserts that the historical trauma of the racial conflict experienced today originated with the country's history of slavery. Degruy asserts that PTSS is not specific to blacks in America; unfortunately, everyone is a recipient of this emotional phenomenon.

\section{Suggestions for Future Research}

If this study is revisited in the future, the recommendation is proposed to expand the population pool to include more than the number of participants included in this transcendental phenomenological study and the inclusion of female participants. The studies would provide a 
broader exploration on the topic of racial reconciliation. These improvements to the protocol can provide an equitable representation of the participants from different regions of the country, which can create a robust data analysis of findings. As a result of this study, I am inspired to continue conducting research on the topic of racial reconciliation and rehabilitation from racists ideologies. Therefore, the following suggestions for future research:

\section{Exploration of the reduction of racial prejudice through the examination of implicit}

bias. This proposed area of research is based on some participants in the study affirming the challenges they faced in recovering from the racist environments and ideologies they were exposed to. It is also based on when the participants began to discover the differences from what they had been taught versus what they learned on their own after exploring literature and being exposed to black culture.

Olson (2003) conducted research related to reducing automatically-activated racial prejudices through implicit evaluation conditioning. In his study, Olson argues that automatic racial prejudice is difficult to change and posits that the most effective means of avoiding prejudicial responses is through motivated processes preventing it from influencing judgments and behavior (p. vi). Olson identified previous research conducted that showed that individuals were unaware of the prejudices they manifested, and through the implicit evaluative conditioning process, the ideologies were substantially reduced.

Exploration of child development on learned behavior and racism. All participants acknowledged that they were taught about race and racism at an early age in the home, with the father being the primary advocate of racial inequality, stereotypes, and discrimination. The continued development of education programs during formative years may provide dividends in neutralizing the attention towards skin color and white privilege and in helping children to embrace the character of individuals.

Exploration of racial reconciliation through restorative justice. Restorative justice is a communication process that "repairs the harm caused by crime. When victims, offenders and community members meet to decide how to do that, the results can be transformational" (Center for Restorative Justice, 2018, n.p.). The use of restorative justice sessions among the judicial system with victims and offenders has proven very productive and resulted in reconciliation through communication between the victims and offenders and a discussion on how the offense impacted the victim. I propose that restorative justice be implemented in the same manner for reconciling past harm related from racial antipathy. Robert Coates, Mark Umbreit, and Betty DeVos (2006) suggest that individuals and groups have the potential to decrease hate and prevent bias-motivated crimes by employing restorative justice. Restorative justice is an effective process for reconciliation with hate-based incidents. I also propose that restorative justice can be a useful process for blacks and whites to discuss the past harms of racism. This aligns with the work by Degruy on post traumatic slave syndrome. Hansen and Umbreit (2018) theorize that the value of implementing regenerative justice is beyond the restorative stage. The use of restorative justice to repair the historical trauma that affects both black and whites in America can be helpful through the use of restorative justice.

Relationship between religious organizations and communities to promote racial reconciliation. There are racial reconciliation groups that are evolving from churches and college campus programs that focus on diversity and equality (see Appendix E). In most of the sources explored, the role of the church has been predominant in facilitating the bridging of the gap between race relations, particularly between members of the black and white races. The groups 
that have established themselves in the community have proven to be successful outlets for promoting racial understanding and reconciliation. This is an interesting phenomenon in recent years and is a different approach from the past. In some denominations and churches, racial conflict divided the races and is a painful historical past. The Southern Baptist Convention in the United States experiences racial divisions that date back to slavery (Williams \& Jones, 2017). From 1845 to 2007, the Southern Baptist Convention was a historically active proponent of slavery, white supremacy and $\mathrm{Ku}$ Klux Klan. In 2007, the convention publicly acknowledged their past was not compliant with Biblical scripture that all men are created equal and extended a public apology for their past role in racial hatred and discrimination (Williams \& Jones, 2017). Future research on the relationship with the church and racial disparities may aid in facilitating an understanding of misrepresented narratives about ethnic minority groups.

\section{Conclusion}

This study contributes to the field of conflict analysis and resolution by providing insightful exploration into the mental and social conflict as it relates to racial antipathy and reconciliation between the black and white races. The goal of the study was to present research that may aid in facilitating the discussion and program development on racial reconciliation and understanding how to move from superficial relationships to meaningful relationships and dialogues built on dignity and respect.

One aspect of the study explored the theories of evil and hate and the progression from evil to hate, which can be manifested from an individual or group's fear that another individual or group will benefit from what may be offered, for example, housing, employment, educational opportunities. Good and evil are the foundational precepts of the will of man. From evolution of mankind, good and evil has been indelible characteristics of humanity and from a Biblical perspective, good and evil has been defined as the origin of the sin nature of man and the will for man to choose good or evil in their behavior. With the recent rise in racially motivated crimes, academic and Biblical scholars such as Ken Ham, Charles Ware, Jim Wallis, Janis Williams, Kevin Jones, and Joy Degruy assert that racism is a "heart sin," and the only way to expunge racism is to repair the heart.

In addition to the aforementioned scholars' assertion of embedded evil and hate, the findings identified in this study also purport that racist ideologies have been perpetuated by misrepresented assumptions chronicled in historical narratives and family history that have caused great harm to the fabric of interracial relations and blended communities in America. The research accomplished in this study affirms that the condition to change the mindset of others also relates to social psychology and racial reconciliation. Dr. Olson's work with reducing automaticallyactivated racial prejudices through implicit evaluation conditioning. Dr. Joy Degruy's research on post-traumatic slave syndrome and her assertion that racism in America is the original sin of the country is not alone in her assertion that racism is the sin of America and her conclusions are supported by Ken Ham, Charles Ware, Jim Wallis, Janis Williams, and Kevin Jones.

When considering changing the racial climate in the United States, questions to ponder include, "can racism be eradicated, and what would it take to do so? "Can there be a culture of Utopia and universal acceptance of those racially and ethnically different from others?" "Is prejudice a built-in phenomenon of the human DNA that cannot be changed?"

In closing, through participant narratives, such as the ones presented in this study, and opportunities to offer safe social settings for diversity dialogues and recovery groups that focus on 
racial trauma, there will be opportunities to begin exploring the repair to historical harm from the past. This can also help individuals, groups, and communities learn from the past though constructive dialogues and cultural immersion between the black and white races. Race, racial antipathy, and skin color are complicated issues that have universally impacted social harmony.

\section{References}

Aguirre, A., \& Turner, J. H. (2009). American ethnicity: The dynamics and consequences of discrimination. New York, NY: McGraw Hill.

Ahmed, M. (2016). Ethnicity, identity and group vitality: A study of Burushos of Srinagar. Journal of Ethnic and Cultural Studies, 3(1), 1-10.

Alexander, M. (2012). The New Jim Crow: Mass incarceration in the age of colorblindness. New York: The New Press.

Ash, S. V. (2010). The black experience in the civil war south. Omaha, NE: Potomac Books.

Baptist, E. (2014). The half has never been told: Slavery and the making of American capitalism. Philadelphia, PA: Basic Books.

Blazak, R. (2004). "Getting It": The role of women in male desistance from hate groups. In A. L. Ferber (Ed.), Home-grown hate: Gender and organized racism (pp. 161-179). New York: Routledge.

Branch, T. (1988). Parting the waters: America in the King years 1954-63. New York: Simon \& Schuster.

Bullard, R. D. (2000). Dumping in Dixie: Race, class, and environmental quality (3 ${ }^{\text {rd }}$ ed.). New York, NY: Routledge.

Corona, R., Velazquez, E., McDonald, S., Avila, M., Neff, M., Iglesias, A., \& Halfond, R. (2017). Ethnic labels, pride, and challenges: A qualitative study of Latinx youth living in a new Latinx destination community. Journal of Ethnic and Cultural Studies, 4(1), 1-13.

Center for Justice and Reconciliation (2018). About us. Retrieved from: http://restorativejustice.org/about-us/leadershipteam/\#sthash.xpQBNZuy.PzFFYs5g.dpbs.

Coates, R.B., Umbreit, M.S., \& Vos, B. (2006). Responding to Hate Crimes through Restorative Justice Dialogue. Contemporary Justice Review, 9(1), 7-21. DOI: $10.1080 / 10282580600564784$.

Conservative vs. Liberal Beliefs (2018, January 16). Senator Cory Booker RIPS DHS Secretary Kirstjen Nielsen Over Defending Trump's Sh*hole Remarks. Retrieved from https://www.youtube.com/watch?v=9-y-ganpnlo

Creswell, J.W. (2009). Research design: Qualitative, quantitative, and mixed methods approaches ( $3^{\text {rd }}$ ed.). Thousand Oaks, CA: SAGE Publications, Inc.

Creswell, J. W. (2012). Creswell, J. W. (20012). Qualitative inquiry and research design: Choosing among five approaches ( $2^{\text {nd }}$ ed.). Thousand Oaks, CA: SAGE Publications, Inc.

Creswell, J.W., \& Poth, S. N. (2018). Qualitative inquiry and research design: Choosing among five approaches $\left(4^{\text {th }}\right.$ ed.). Thousand Oaks, CA: SAGE Publications, Inc.

Curtin, P. D. (1972). The Atlantic slave trade: A census. Madison, WI: University of Wisconsin Press.

Darwin, C. (1958). The origin of species: By means of natural selection of the preservation of favoured races in the struggle for life. New York, NY: New American Library.

Darwin, C. (1981). The descent of man and selection in relation to sex. New Jersey, NJ: Princeton University. 
DeGruy, J. A. (2005). Post Traumatic Slave Syndrome: America's legacy of enduring injury and healing. Portland, OR: Joy DeGruy Publications.

Delgado, R., \& Stefancic, J. (2012). Critical race theory: An introduction. New York, NY: New York University Press.

DiLorenzo, T.J. (2002). The Real Lincoln: A New Look at Abraham Lincoln, his agenda, and his unnecessary war. Roseville, CA: Prima Publishing.

Dovidio, J. F., Gaertner, S. E., Kawakami, K., \& Hodson, G. (2002). Why can't we just get along? Interpersonal biases and interracial distrust. Cultural Diversity and Ethnic Minority Psychology, 8(2), 88-102.

DuBois, W. E. B., (1998) [1899]. The Philadelphia negro: A social study. Philadelphia: University of Pennsylvania Press.

Dyson, M. E. (2017). Tears we cannot stop: A sermon to White America. New York, NY: St. Martin's Press.

Fitzhugh, G., \& Woodward, C.V. (Eds.) (1988). Cannibals all! Or slaves without masters. Cambridge, MA: Harvard University Press.

Fleury, B. (2015). The negro project: Margaret Sanger's diabolical, duplicitous, dangerous and deadly plan for black America. Pittsburgh, PA: Dorrance Publishing Co.

Foner, E. (2005). Forever free: The story of emancipation and reconstruction. New York, NY: Vantage Books.

Gabe, R. F. (2016). Phenomenological research study on unexpected loss for the adult sibling: Exploring interpersonal conflicts. (Unpublished doctoral dissertation). Nova Southeastern University, Ft. Lauderdale.

Garrow, D. J. (2004). Bearing the cross: Martin Luther King, Jr. and the southern Christian leadership conference. New York, NY: HarperCollins Publishers, Inc.

Gould, S. J. (1977). Ontogeny and phylogeny. Cambridge, MA: Belknap Press.

U.S. Government Accountability Office (2017, April). Countering Violent Extremism: Actions Needed to Define Strategy and Assess Progress of Federal Efforts. (Publication No. GAO17-300). Retrieved from: https://www.gao.gov/assets/690/683984.pdf.

Griffith, D.M., Mason, M., Yonas, M., Eng, E., Jeffries, V., Plihcik, S., \& Parks, B. (2007). Dismantling institutional racism: Theory and action. American Journal of Community Psychology, 39(3-4), 381-392.

Hansen, T., \& Umbreit, M. (2018). Regenerative justice, beyond restoring. Contemporary Justice Review: Issues in Criminal, Social, and Restorative Justice (in press), 1-23.

Ham, W., \& Ware, C.A. (2007). One race and one blood. Green Forest, AK: Master Books.

Harris, T. (1984). Exorcising blackness: Historical and literary lynching and burning rituals. Indianapolis, IN: Indiana University Press.

Herrnstein, R. J., \& Murray, C. (1994). Bell curve: Intelligence and class structure in American life. New York, NY: Simon and Schuster.

Hitler, A. (1941). Mein Kampf. New York, NY: Reynal \& Hitchcock.

Husserl, E. (1931). Ideas: General introduction to pure phenomenology. New York, NY: Routledge.

Jordan, W. D. (1996). White over black: American attitudes toward the negro, 1550-1812. Chapel Hill, NC: University of North Carolina Press.

Kendi, I. X. (2016). Stamped from the beginning: The definitive history of racist ideas in America. New York, NY: Nations Book.

Levine, B. (2005). Half slave and half free: The roots of civil war. New York, NY: Hill and Wang. 
Levinson, J. D. (2007). Forgotten racial equality: Implicit bias, decision-making, and misremembering. Duke Law Journal, 57, 345-424.

Leyden, T. J., \& Cook, M. B. (2008). Skinhead confessions: From hate to hope. Springville: Sweetwater Books.

McCausland, P., Saliba, E., Saliba, E., Donohue, E., \& Donohue, M., (2017, August 12). Charlottesville Rally Turns Deadly: One Killed After Car Strikes Crowd. U.S. News. Retrieved from: https:/www.nbcnews.com/news/us-news/charlottesville-rally-turnsdeadly-one-killed-after-car-strikes-crowd-n792116.

Mascaro, L (2016, November 18). White nationalists dress up and come to Washington in hopes of influencing Trump. The Los Angeles Times. Retrieved from http://www.latimes.com/nation/la-na-pol-white-nationalists-thinktank-20161119story.html

Mauch, J., \& Tarman, B. (2016). A historical approach to social studies laboratory method. Research in Social Sciences and Technology, 1(2), 55-66.

McCullough, D. (1992). Truman. New York, NY: Simon \& Schuster.

Meeink, F. (2009). Autobiography of a recovering skinhead: The Frank Meeink story - as told to Jody M. Roy. Portland, OR: Hawthorne Books.

Michaelis, A. (2012). My life after hate. Milwaukee, WI: Authentic Presence Publications.

Moore, J. H. (Ed.). (2007). Encyclopedia of race and racism. ( $3^{\text {rd }}$ ed.). New York, NY: MacMillan.

Mohr, J. M. (2010). Leaving is possible: The psychological and sociological mechanisms of desistance from White supremacist organizations and racist ideologies. (Order No. 3407593, Gonzaga University, Spokane, Washington). ProQuest Dissertations and Theses, 366-n/a. Retrieved from http://search.proquest.com.ezproxylocal.library.nova.edu/docview/366579251?accountid $=6579$

Moustakas, C. (1994). Phenomenological research methods. Thousand Oaks, CA: SAGE Publishing.

Omi, M., \& Winant, H. (2015). Racial formation in the United States. New York: Routledge.

Onyalla, D. B. (2018). Ethnic Influence of Colleagues and Friends on Choices of News Media Channels: The Case of Catholic Church Leaders in Nairobi, Kenya. Journal of Ethnic and Cultural Studies, 5(2), 140-158.

Patton, M. (2002). Qualitative research and evaluation methods (3rd ed.). Thousand Oaks, CA: SAGE Publications.

Pew Research Center (2013, August 22). "King's Dream Remains an Elusive Goal; Many Americans See Racial Disparities." Pew Research Center's Social \& Demographic Trends Project. Retrieved from: http://www.pewsocialtrends.org/2013/08/22/kings-dreamremains-an-elusive-goal-many-americans-see-racial-disparities/.

Picciolini, C. (2017). American youth: My descent into America's most violent hate movementand how I got out. New York: Hatchette Book Group Inc.

Potok, M. (2013a, Spring). The Year in Hate and Extremism. Southern Poverty Law Center Intelligence Report, Spring 2013 Issue.

Potok, M. (2013b, Fall). Leaving White nationalism. Southern Poverty Law Center - Intelligence Report, (1), 37-42.

Roberts, G. \& Klibanoff, H. (2006). The race beat: The press, the civil rights struggle, and the awakening of a nation. New York, NY: Random House. 
Rosenberg, Y. (2017, August 14). 'Jews will not replace us': Why white supremacists go after Jews. The Washington Post. Retrieved from https://www.washingtonpost.com/news/actsof-faith/wp/2017/08/14/jews-will-not-replace-us-why-white-supremacists-go-afterjews/?utm_term=.a961e604255a.

Schaefer, J.R., \& Navarro, J. (2003, March). The Seven-Stage Hate Model: The Psychopathology of Hate Groups. FBI Law Enforcement Bulletin. Retrieved from http://www.au.af.mil/au/awc/awcgate/fbi/7stage_hate_model.htm

Simi, P. (2003). Rage in the city of angels: The historical development of the skinhead subculture in Los Angeles. (Unpublished doctoral dissertation). University of Nevada, Las Vegas).

Tarman, B. (2017). From the Editor-Editörden. Journal of Social Studies Education Research, 8 (1), 1-3. Retrieved from http://dergipark.org.tr/jsser/issue/29488/316353

Van Manen, M. (1990). Researching lived experience: Human science from an action sensitive pedagogy. London, Ontario, Canada: University of Western Ontario.

Wallis, J. (2016). America's Original Sin: Racism, White privilege, and the Bridge to a New America. Grand Rapids, MI: Brazos Press.

Ward, J. M. (2015, June 19). Dylann Roof and the white fear of a black takeover. Los Angeles Times. Retrieved from http://www.latimes.com/opinion/op-ed/la-oe-0621-wardcharleston-ame-shooting-20150619-story.html.

Washington, H. A. (2006). Medical apartheid: The dark history of medical experimentation on Black Americans from colonial times to the present. New York, NY: Doubleday.

Williams, J. J., \& Jones, K. M. (2017). Removing the stain of racism from the Southern Baptist Convention. Nashville: B \& H Academics.

West, C, (2001). Race matters. Boston, MA: Beacon Press.

Williams, D. R. \& Mohammed, S. A. (2013). Racism and Health I: Pathways and Scientific Evidence. American Behavioral Scientist, 57(8), 1152-1173.

Willis, J. W. (2007). Foundations of qualitative research: Interpretive and critical approaches. London, England: SAGE Publications.

Worthington, E. (2001). Five steps to forgiveness. New York, NY: Crown Publishing.

Zangrando (1980). National Black Law Journal, 7(3), 446-450. Retrieved from https://escholarship.org/uc/item/1m71j2dk.

Manuscript received May 08, 2019

Final revision received May 14, 2019

Accepted May 30, 2019 